\title{
Lo que contienen los abrazos. El sentido ontológico, cronológico y cósmico-religioso del amor a partir del pensamiento de Bernhard Welte
}

Ángel E. Garrido-Maturano*

\section{Resumen}

El artículo parte de la Dialéctica del amor de Bernhard Welte para realizar un análisis hermenéutico-fenomenológico del sentido ontológico, crono-lógico y cósmico-religioso del eros. El análisis persigue tres objetivos. Primero mostrar cómo la reconocida facultad cognoscitiva del amor, que le permite ver la particularidad del tú amado de un modo inaccesible al conocimiento objetivo, desemboca

\footnotetext{
Nacido en el año 1964 en Buenos Aires; estudios de Filosofía en la Universidad de Buenos Aires y de Friburgo de Brisgovia. En 1996 Doctor en Filosofía por la Universidad de Buenos Aires. Tesis: Fundamentos, determinación y testimonio de la relación ética en el pensamiento de E. Levinas. Becario postdoctoral de la Alexander von Humboldt Stiftung. Más de 100 publicaciones en 13 países entre artículos y libros. Publicaciones escogidas: "Illeität im Denken von E. Lévinas. Vom Vorbeigehen der Illeität bis zum Zeugnis der Liebe Gottes" en Philosophisches Jahrbuch 103/1 (1996): 62-75. La Estrella de la Esperanza. Introducción a La Estrella de la Redención de Franz Rosenzweig desde una perspectiva fenomenológica (Buenos Aires: Academia Nacional de Ciencias, 2000); Sobre el abismo. La angustia en la filosofía contemporánea (Buenos Aires: Adriana Hidalgo, 2005). "Die Erfüllung der Kunst im Schweigen. Bemerkungen zu Franz Rosenzweigs Theorie der Kunst", in Théologie negative, Archivio di Filosofia 27, (2002): 695-720. Los tiempos del tiempo. El sentido filosófico, cosmológico y religioso del tiempo (Buenos Aires: Biblos, 2011). Principales cargos: desde 1998 miembro del Centro de Estudios Filosóficos de la Academia Nacional de Ciencias de Buenos Aires; investigador independiente del Consejo Nacional de Investigaciones Científicas y Técnicas. Desde 2004 profesor de Filosofía de la Universidad Católica de Santa Fe. Desde 2010, profesor del doctorado de la Facultad de Filosofía y Teología de la Universidad del Salvador, Buenos Aires. Institución de pertenencia: CONICET, IIGHI, Resistencia, Argentina. Contacto: hieloypuna@hotmail.com.
} 
en un acontecimiento ontológico con-creativo. Segundo, elucidar la sincronía como la temporalidad esencial al eros en tanto acontecimiento. Finalmente, explicitar en qué medida el amor erótico es el acontecimiento-signo de una armonía de índole cósmico-religiosa que vincula a los amantes con todas las cosas.

\title{
Palabras clave
}

Welte, amor, concreatividad, sincronía, cosmos.

\section{It hugs containing. The ontological, chronological, and cosmic-religious sense of eros thinking from Bernhard Welte}

\begin{abstract}
On the basis of Bernhard Welte's Dialectic of Love, the article develops a hermeneutic-phenomenological analysis of the ontological, chronological, and cosmic-religious meaning of eros. The article has three purposes. First, it attempts to show how the acknowledged cognitive capacity of love, which enables to see the particularity of the loved thou in a way that is inaccessible to objective knowledge, leads to an ontological con-creative event. Second, an elucidation of synchrony as the temporality essential to eros as an event is advanced. Finally, the article shows the degree in which erotic love is the sign-event of a cosmic-religious type of harmony that links lovers with all things.
\end{abstract}

\section{Keywords}

Welte, love, concreativity, synchrony, cosmos. 


\section{Introducción}

Las palabras que siguen, surgidas de la lectura de un bello ensayo de Bernhard Welte ${ }^{1}$, hablarán de un fenómeno tan común $y$, sin embargo, inefable; tan inevitable $y$, sin embargo, huidizo; tan íntimo y, sin embargo, universal. Las palabras que siguen hablarán de amor. Ellas, como tantas otras que las precedieron y como muchas otras que las seguirán, no podrán asirlo. ¿Quién podría definir el amor? ¿Quién pretendería agotar en conceptos lo que no han podido agotar los versos mejores de los mejores poetas? No transita ese desatinado camino el autor. Su intención es modesta: elucidar las implicancias de algunos aspectos del sentido del amor a partir del (ciertamente luminoso) análisis fenomenológico que de él hace Bernhard Welte.

Cuando digo amor pienso aquí fundamentalmente en el amor entre un hombre y una mujer, en el pathos erótico ${ }^{2}$. Cuando me refiero al sentido, pienso en aquellos rasgos esenciales que hacen de la relación entre un yo y un tú una relación precisamente erótica. Que tome como punto de partida el modo específico en que estos rasgos se dan en el amor erótico no significa que muchos de ellos no se concreten, de modos sin duda diversos, en otros tipos de relación amorosa entre un yo y un tú humano, particularmente en el amor ético o amor al prójimo. Aunque innumerables sean las formas del

Bernhard Welte, "Dialektik der Liebe", en Gesammelte Schriften, Band V/1: Geistliche Schriften (Freiburg im Breisgau: Herder, 2009).

Hago aquí una aclaración que personalmente considero obvia, pero que la experiencia me ha enseñado que es inevitable una y otra vez repetir. No es posible hablar desde ningún lado. Fenómeno significa la cosa en el cómo de su darse, en cuanto todo lo que se da, se da en una cierta perspectiva y dentro de un horizonte. Si esto es valedero para cualquier fenómeno, por ejemplo, una silla, tanto más para uno tan íntimo y personal como es el eros. Por lo tanto, el autor solo puede abordar fenomenológicamente el tema desde su propio horizonte de comprensión y perspectiva, correlativos ambos al modo mismo en que se le da el fenómeno. Ello implica hacerlo en el horizonte del eros vivido como relación entre un hombre y una mujer y desde la perspectiva de un hombre. Nada obsta para que los rasgos esenciales a los que aquí se accederá desde el análisis del darse de la cosa (el pathos erótico) en un horizonte (el heterosexual) y desde una perspectiva (la masculina) determinados no puedan reencontrarse desde horizontes y perspectivas diferentes de experimentar el amor. Hablar desde otro horizonte sería una mentira. Hablar desde todos, una generalidad en el peor sentido del término, una mera abstracción, una imposibilidad. 
amor, comparto con B. Welte, como él lo hacía con J. Pieper³, la idea de que todas ellas tienen algo en común o, mejor dicho, que todas ellas están dirigidas a una forma consumada que las vincula unas con otras. Que hable de sentido en términos de rasgos esenciales no significa, como adelantaba, que se pretenda agotar el eidos del amor ni definir absolutamente su esencia. Partiendo de los análisis de Welte, me contento con llamar la atención sobre algunas características esenciales de la forma consumada del fenómeno, y ello en razón de la importancia ontológica, cronológica ${ }^{4}$ y cosmológico ${ }^{5}$-religiosa que asume dicha consumación. De acuerdo con ello el estudio del texto weltiano persigue tres objetivos. En primer lugar, mostrar cómo esa facultad cognoscitiva, específica del amor y que tantas veces le fuera con justicia reconocida, a saber, la de poder-ver al otro y alcanzar en él lo que el conocimiento objetivo no ve ni el entendimiento alcanza -las razones del corazón que la razón no entiende- desemboca en un acontecimiento ontológico de carácter con-creativo. En segundo lugar, elucidar la sincronía como la temporalidad esencial al eros en tanto acontecimiento. Y, finalmente, explicitar en qué medida el amor erótico es signo de una armonía de índole cósmico-religiosa que vincula a los amantes con todas las cosas. Aquella armonía que le permite confesar al enamorado: "por ti amo el universo".

Permítaseme alguna rispidez sobre el método. Tiene dos momentos. El primero, hermenéutico, siempre al servicio del segundo, fenomenológico. A conciencia carece, empero, de toda innecesaria (para las intenciones de este trabajo) pretensión histórico-filológica. Dicho de otro modo: estas consideraciones ni se proponen ni cobijan

3 Cf. Bernhard Welte, op. cit., 78.

4 El término crono-lógico no es usado aquí en el sentido habitual de medición del tiempo, sino en el etimológico de un logos sobre cronos, esto es, en el sentido de aquello (logos) a partir de lo cual es comprensible el darse del tiempo (cronos) en el fenómeno del amor, o, dicho de otro modo, de aquello que reúne o congrega la temporalización del tiempo en las relaciones eróticas.

5 El término cosmo-lógico nuevamente no es usado aquí en el sentido usual de una especulación sobre el cosmos concebido como totalidad de los astros estelares, sino en el etimológico de un logos sobre el cosmós, esto es, en el sentido de aquello (logos) a partir de lo cual es comprensible el darse el mundo como un orden (cosmós) en el fenómeno del eros o, en otros términos, de aquello que reúne o congrega las distintas apariciones del mundo en las relaciones eróticas. 
en su hermenéutica el interés de realizar una reconstrucción erudita o completa de la concepción weltiana del amor. Mucho menos aún de la de los otros autores a las que ellas eventualmente se refieran. Aquí lo que importa es explicitar y desarrollar las implicancias ontológicas, cronológicas y cosmológicas latentes en la fenomenología weltiana del eros. Para ello habremos de valernos de la interpretación, concebida como una elucidación de aspectos aludidos en el texto del autor y desplegada a través de la libre puesta en diálogo del pensamiento de Welte con el de otros autores -en especial M. Scheler, V. Solov'ev y L. Binswanger- a efectos de que, por obra de ese diálogo, lo aludido sea mejor elucidado. Pero la interpretación-el momento hermenéutico- está al servicio de un segundo momento fenomenológico, que es ciertamente el fundamental, y que no consiste sino en traer explícitamente a la luz lo esencial que ya siempre se ha mostrado en el amor que todo hombre experimenta, aunque muchas veces se muestre de modo desfigurado, incompleto o implícito. La interpretación de los textos no tiene otro fin, pues, que dejar ver lo que se da tal cual ello se da y desde el cómo de su darse mismo ${ }^{6}$, en la medida en que ella debiera, en primer lugar, ayudarnos a apartar todo reduccionismo que desfigure el amor o que empobrezca su sentido, incluso a veces de un modo penosamente prosaico, y a restituir el fenómeno a su entero horizonte de significación. En segundo lugar, en la medida en que la interpretación trae también explícitamente a la luz aquello esencial que, por lo pronto y la mayor parte de las veces,

No debe entenderse este "dejar ver", en el caso de Welte, como una pura pasividad receptiva del pensamiento, sino que hay que comprender siempre este pensar que deja ver en el contexto general de la fenomenología como pensamiento correlativo. En tal sentido el pensamiento que deja ver y el mostrarse se pertenecen uno a otro. Pensar no es, pues, solamente receptivo o fenomenológicamente pasivo, sino activo, en tanto es aquello que concede a lo que se muestra desde sí mismo el poder ser visto desde sí. En relación con este aspecto del método fenomenológico weltiano, que aquí seguiremos, escribe uno de sus tres principales discípulos y heredero de la cátedra de Filosofía de la Religión en Friburgo, Klaus Hemmerle: "Seguramente están en relación recíproca lo que se da a ver y el ver mismo y por cierto de modo tal que respectivamente el comienzo del uno es ya la emergencia del otro. Las estructuras se corresponden, pero en su correspondencia son la apropiación de aquello que a ambos, mostrarse y ver, dejar ver y ver, los remite uno a otro y los reúne uno con otro." Klaus Hemmerle, "Eine Phänomenologie des Glaubens - Erbe un Auftrag von Bernhard Welte", en Fragend und lehrend den Glauben weit machen. Zum Werk Bernhard Weltes anlässlich seines 80. Geburtstages, ed. K. Hemmerle (München/Zürich: Verlag Schnell und Steiner, 1987), 111. 
se muestra encubierto entre la multiplicidad inagotable y tristemente no consumada de las manifestaciones del amor, y que, precisamente por ello, suele caer en el olvido. "Pero -como escribe el propio Welteprecisamente esto significa trabajar fenomenológicamente. Traer, a través del esfuerzo del pensar, al abierto mostrarse-a-sí-mismo, lo que ya está presente en lo encubierto"7.

\section{Entre tú y yo el origen. Sobre la emergencia del fenómeno erótico}

Ciertamente, tenía razón cuando reiteraba la consabida sentencia acerca de la indefinibilidad del amor. Pero no la tenía meramente porque "nos falten palabras" para definirlo o por "su infinita variedad", sino porque el amor es un fenómeno originario, esto es, algo que se da desde sí mismo y por sí mismo y que no puede derivarse de otros fenómenos concomitantes. Bien puede que conozca a fondo a mi amada y la comprenda bien, pero ni la mucha comprensión, ni la familiaridad del trato, ni la justificada admiración, ni el debido respeto, ni ningún otro vínculo concomitante, de la naturaleza que fuere, puede fundamentar el amor. Y es que el amor no tiene fundamento. Simplemente acaece. De su falta de fundamento dan testimonio la infinidad de amores inconvenientes, de pasiones erróneas, de deseos trágicos. Él es, pues, un fenómeno inicial, que solo puede ser comprendido desde sí mismo, y no obtenido como derivación de otro fenómeno cualquiera. Es ese mismo carácter de cualidad originaria, comparable con la de un color, lo que lo vuelve inexplicable por otra cosa que no sea por sí mismo. Tan imposible es derivarlo de otros fenómenos, como hacer comprender a un ciego el celeste en base a sutiles disquisiciones conceptuales. Eros solo puede ser reconocido y descripto desde sí mismo y en su propia cualidad.

Desde sí mismo y en su propia cualidad se muestra el amor erótico como una correlación que acaece porque sí -el amor es origi-

7 Bernhard Welte, op. cit., 79. 
nario- entre un determinado yo amante y un determinado tú amado. Lo que origina la correlación -el porque sí- podría explicitarse tal vez del siguiente modo: que ese tú sea para este yo el tú que ella es. ¿Por qué resulta que ese tú es para este yo el objeto de amor? Ello ya no admite respuesta. Que el amor acaece, que es originario, no significa, pues, otra cosa que él resulta de un específico modo de salirme ella al encuentro precisamente a mí. A este origen del amor, que solo se pertenece a sí mismo, podríamos llamarlo, con Welte, "lo personal"8. Allí donde el yo y el otro se sirven uno del otro en un plexo de conveniencias racionales mutuas no está presente eros. Recién cuando el otro le sale al encuentro al yo como un tú insustituible para ese yo -como un tú que no puede convertirse sin más en un ella como otras tantas ellas- el amor hace su entrada. Amar es afirmar con todo nuestro ser ese ser personal de la amada que ha despertado el amor. Pero como el amor se da en una correlación ${ }^{9}$ la afirmación de lo personal de la amada como esencial para ser quien yo soy es, también y a la par, un descubrimiento y una afirmación del ser personal de mi yo amante. En efecto, amando a ese tú, el amante ama ser el yo para quien el tú es ese tú amado. "Todos mis pensamientos están contigo, ésta es la canción del amor, pero quien la dice o la canta se alegra de ser él quien la puede decir o cantar"10 Si amar es descubrir en ella lo esencial o personal que me deja a mí

$8 \quad$ Ibíd., 80.

9 Correlación no significa aquí lo mismo que correspondencia. El hecho de que el amor no sea correspondido no significa que el tú amado no aparezca como tal en correlación con un determinado yo amante, ni que el yo que ama desinteresadamente y deja ser libremente a la amada imposible no afirme, en esa renuncia, tanto su yo propio yo amante como el tú de ella. Nuevamente Hemmerle: "Yo te dejo libremente ser, no en la medida en que me desentiendo de ti, sino en la medida en que procuro ver, sentir, comprender desde ti. (...). Yendo desde ti hacia mí, voy a la vez desde mí hacia ti, precisamente en ese acto que significa tanto dejar libre como llevarte conmigo. Así acontece en mí mismo una relación pericorética, un 'tú en mí y yo en ti'". Klaus Hemmerle, "Wahrheit und Liebe - ein perichoretisches Verhältnis", en Klaus Hemmerle, Ausgewählte Schriften. Band II: Unterwegs mit dem dreieinen Gott Schriften zur Religionsphilosophie und Fundamentaltheologie I (Freiburg i. B: Herder, 1996), 320. Precisamente lo que Hemmerle llama relación pericorética es lo que aquí llamamos correlación. Además, si bien es cierto que un amor no correspondido no puede consumarse ni alcanzar su significación plena, no lo es menos que el amor no acaece ni por ni para ser correspondido, y que, por tanto, su origen correlacional no resulta de la correspondencia. 
convertirme en quien en verdad soy, afirmar la persona en la amada es, a la vez, descubrir y afirmar mi propia persona.

Esta doble afirmación que ocurre en el amor, precisamente porque acaece sin un fundamento, lo hace al modo de un don. "El amor es esencialmente algo así como un regalo"11, afirma Welte. Ser amado es un don que se recibe sin quererlo y sin haber hecho ninguna otra cosa que ser para merecerlo. El amor le ocurre al hombre -lo singulariza en dativo-. A veces y solo a veces -sin razón objetiva alguna- le sale al encuentro y lo toma dichosamente de improviso. Él es, como afirma Welte, una suerte de virtus infusa. Por ello mismo cada acto de amor surge, en verdad, de una pasividad originaria. "Lo que el amante hace, lo recibe de regalo"12. Le es dado el amor que da y que, ahora, en la intensidad del pathos, es el núcleo mismo de su ser. Se produce así una doble paradoja ontológica. Primero: la paradoja de un ser que es mi ser más propio, pero que no es mío, pues se origina en mí pero no por mí. Segundo: la de un ser que crece dándose, pues más amor tengo en tanto más amor doy. El amor se alimenta de su propio darse. Eros se nutre de sí mismo.

Se abre así y aquí, como resultado de la propia descripción de la emergencia del fenómeno erótico, a saber, de este acaecer del amor como el don o el regalo de una correlación originaria entre un yo específico y un tú específico para ese yo, una doble problemática. Por un lado, una problemática ontológica: ¿̇en qué medida el amor, afirmando el ser del yo amante, renovado por el amor que ha recibido, y del tú amado, a quién le da ese ser que a él mismo le ha sido regalado, no re-genera a ambos? ¿No es el amor fructífero, activo en términos ontológicos? ¿Cómo comprender esa actividad ontológica del eros?

Por otro lado, una problemática que podríamos llamar cósmicoreligiosa, en un sentido muy preciso, a saber: en cuanto el yo amante, amando en y por el tú todas las cosas con un amor que él antes recibió

11 Ibíd., 83

12 Ídem. 
como un don, se liga con el mundo todo y se religa con un misterio que primero se ligó con él dándole la posibilidad de amar. Se trata del misterio del origen de un fenómeno que padezco, pero que no encuentra ni en mí espontaneidad ni en nada objetivo causa alguna que lo fundamente de modo suficiente, y que, por eso, podemos decir que emerge desde sí mismo. Se trata, en síntesis, del misterio del darse y extenderse del don; del infundirse y difundirse de la virtus infusa.

Pero si nosotros continuamos meditando más de cerca en este carácter de regalo propio del amor y en la irreductibilidad de su origen habremos de convenir que, desde la perspectiva funcionalutilitaria que organiza nuestro mundo cotidiano, el amor es un instante milagroso ${ }^{13}$. Él se presenta como la felix hora que quiebra la continuidad de las horas. Como un instante im-pre-visible que in-curre en el presente sin ser el resultado del dis-currir extático de ningún pasado rememorable. ¿Cómo podría mi pasado, mi ser-sido, haber engendrado este presente feliz, si en el pasado ella no estaba allí? Si es cierto que el amor deja atrás mi entero pasado a partir de un presente nuevo, no lo es menos que él no reconoce ya como suyo el advenir al que ese sido lo pro-yectaba, porque ahora el amante ya no se dirige más a sí desde sí, sino que viene a sí yendo hacia ella. Propiamente la hora feliz en la que la luz del pathos erótico todo lo ilumina se disuelve el futuro. El amante vive en el instante presente del amor, no concibe ni desea futuro alguno fuera de él, pues el presente lo colma y en el ahora en que ve los ojos de la amada se

13 Ciertamente el amor aquí es considerado desde su forma consumada, desde aquella aspiración a la que todo amor concreto entre un tú y un yo tiende y que, por cierto, nunca termina por realizar. Consumación que se vuelve todavía más esquiva en nuestra era tecnológica que, en razón de su propia constitución técnico-instrumental, tiende a relativizar todo absoluto y a supeditar una pasión sin por qué ni para qué a un frío cálculo de los unos y los otros. Se plantea, entonces, como el propio Welte lo hace, la siguiente objeción: ¿̇no deberíamos ser más prudentes, incluso más escépticos y considerar el amor bajo las condiciones relativas, humanas, finitas (a veces demasiado humanas y demasiado finitas) de la existencia cotidiana que poco tienen que ver con historias de grandezas, de absolutos y de milagros. Pero precisamente porque estas formas cotidianas son formas no logradas o caídas de la relación erótica, lo que se testimonia en la insatisfacción que le es usualmente inherente, "no deberíamos nosotros acaso antes que nada atender a las grandes y esenciales dimensiones del amor grande y esencial." Bernhard Welte, op. cit., 84. 
congrega para él el tiempo todo. En la emergencia misma del amor, en el carácter milagroso de esa relación originaria entre un tú y un yo, que representa una excepción de la continuidad causal, acaece, pues, una paradoja crono-lógica: el tiempo fluye escapando de su fluir y haciendo durar en él un reflejo de la eternidad. He aquí la problemática temporal que, como la ontológica y la re-ligiosa, emerge apenas dirigimos la vista al amor en el cómo de su darse y cuando consideramos este cómo por sí mismo y desde sí mismo. Es, pues, el modo en que el amor se da $-\mathrm{y}$ no una intención especulativa- lo que mueve al pensamiento a preguntarse: ¿Qué pasa entre el amor y el ser? ¿Qué pasa entre el amor y el tiempo? ¿Qué pasa entre el amor y el misterio del origen de todo ser y todo tiempo?

\section{El sentido ontológico del amor: el acontecimiento con-creativo}

\subsection{Lo amable}

Es la amada quien pone en movimiento al amor, pues es ella quien se le manifiesta al amante como digna de ser amada. ¿̇Pero qué es propiamente lo amable en ella? ¿Qué mueve al amante a un amor verdadero? A tal pregunta podría un enamorado, tal vez, responder así: "Lo amable es que solo tú eres tú. Tus funciones pueden ser quizás cumplidas por otra. Pero esto: que tú eres tú, no". Lo amable reside, entonces, en el tú mismo de la amada, considerado en su más propia originalidad y originariedad. Reside, escribe Welte: "en el hecho de que esta originariedad se me aparece en su índole propia como sí misma y me hace seña a mí mismo [en mi índole más propia AG]"14. A este aparecérseme primigenio de la particularidad del tú de la amada, a esta expresión de su modo de ser más propio, propone Welte llamarlo lo bello (das Schöne). Aquello que me mueve a amar es, entonces, la índole originaria de mi amada que se me ex- 
presa (o me "hace seña") $a$ mí ${ }^{15}$ en su cuerpo viviente ${ }^{16}$ de una forma bella. El término "bello" no debe ser malentendido. No se mienta aquí, por supuesto, la mera belleza estética de un físico hermoso, sino una forma especial de belleza, a saber, la peculiar armonía del modo de sentir o experimentar el mundo de la amada y de experimentarse a sí misma en esa experiencia del mundo, que se ex-presa y resplandece en el lenguaje mismo que su cuerpo es. Naturalmente se puede considerar de por sí la linda figura, el hermoso rostro, el cuerpo escultural, haciendo abstracción de la impronta y de la fuerza de la persona que se quiere revelar en el medio de la manifestación corporal. Puede uno -y esto es lo que las más de las veces ocurresentirse atraído por el brillo y olvidar lo que brilla ${ }^{17}$. Pero entonces no hay relación personal ni tampoco, por supuesto, amor; o, por lo menos, él aún no ha propiamente comenzado.

Ahora bien, percibimos lo bello no como un mero atractivo, no como la belleza puramente estética, sino como la expresión de una índole bella de ser -como lo propiamente amable- solo cuando con la belleza de la amada aparece para el amante, concomitante e inseparablemente, su bondad. Lo amable es, pues, lo bello y lo bueno. Lo amable es propiamente la " $y$ " que reúne lo bueno y lo bello expresándose juntos en el cuerpo viviente de la amada. ¿Pero es que acaso se relaciona lo amable con lo bueno en un sentido moral? Ciertamente

No debe desatenderse el carácter original correlativo del amor. Se trata de la belleza de un yo determinado que solo se manifiesta como tal para un tú determinado que puede experimentarla como tal. Por belleza del cuerpo no entendemos aquí la mera belleza plástica o puramente física de un cuerpo, que bien puede atraerme estética y excitarme sexualmente, sin que por ello reconozca en él lo amable que me enamora, y que, por eso mismo, rápidamente puede ser sustituida por la atracción tanto o más fuerte que me provoca la belleza sexual de otro cuerpo igualmente hermoso. Se trata, por el contrario, de una belleza no objetiva: de la belleza del cuerpo considerado en su carácter viviente. Por cuerpo viviente habrá que entender el cuerpo en tanto aquello que lleva en sí y expresa el modo que en la amada se siente a sí misma y el modo en que siente todo aquello que (precisamente porque ella se siente a sí misma en su cuerpo) puede afectarla, esto es, el mundo mismo que la rodea. De allí la usual importancia de los ojos de la amada para el enamorado, en cuanto en los ojos, por excelencia, se expresa tanto el sentir-se de la amada a sí misma -su ánimo- cuanto el modo en que siente o experimenta el mundo que la rodea -su temple. Te amo significa amo el modo en que vas hacia el mundo y el modo en que lo recibes. Cuando el amante dice "te amo", en verdad dice: "Amo tu modo de relacionarte con la vida y amo el modo en que la vida se refleja en ti. Y veo ambas cosas en tus ojos, en cada gesto y pliegue de tu cuerpo."

Cf. Bernhard Welte, op. cit., 87. 
lo hace, en cuanto la bondad cualifica de un modo esencial a la persona como tal, y lo amable es lo personal. En efecto, toda persona, aún aquella más despreciable, presenta, no como una característica casual o circunstancia agregada, sino como un rasgo propio de su ser, algún modo de bondad, que precisamente cualifica lo personal en ella, y que, por tanto, es constitutivo de lo amable. Lo bueno, entonces, "co-aparece necesariamente donde aparece lo personal como lo bello personal y mueve el amor"18. La belleza de lo personal -esa particular armonía que el amante y tal vez solo él puede percibir en el cuerpo viviente de la amada- es verdadera y efectivamente tal cuando está transida por lo bueno que vive en ella, y la unión de ambos es lo que en verdad pone en movimiento al amor. Unos bellos ojos azules pueden gustar, pero amar solo se ama lo que los ojos dicen.

Lo amable es, entonces, para Welte, lo bello y lo bueno personal. ¿Pero no nos hemos enamorado acaso de personas que, para ojos menos entusiastas, poco tenían de lo uno y tal vez menos aún de lo otro? Aquí es necesario incluir el devenir. La persona, por cierto, no es un objeto estático, sino que es dinamismo, proyección de sí, devenir. Lo bueno y lo bello que yo (por ser el yo que soy) veo en tu originario modo de ir al mundo y en tu modo igualmente originario de recibirlo está en constante devenir, como tu propio "ser-en-el-mundo". Precisamente porque en tanto "ser-en-el-mundo" la persona es proyección de sí, es ser-posible, lo amable nunca es algo estático. No amo algo definitivamente bello y bueno, sino una persona que, existiendo, adviene hacia lo bello y a lo bueno. Más aún: lo que define el "ver" propio del amor, la "vivencia" que el amante y solamente el amante puede hacer de la amada, es la capacidad que tiene Eros no solo de experimentar la belleza y la bondad que lucen, por así decir, descubiertas y a la luz del día en el rostro de una persona, sino también y esencialmente de des-en-cubrir lo bueno y lo bello que en ella están inertes en acto, pero vivos en potencia. El amor puede ver también, en las potencialidades ocultas o latentes, la luz que brilla en secreto, 
sofocada en la realidad oscura del tú. Él, sin embargo, no ama nunca la oscuridad, sino el débil resplandor: la posibilidad-quizás vaga, quizás incierta- de bondad y de belleza que se esconde tras un rostro endurecido, tras un mutismo hiriente. Y ello porque el amor logra lo que los otros no: experimentar esa bondad posible, ver esa germinal belleza de la amada, y encontrar en ellas lo que necesita el amante para llegar, él también, a ser el sí mismo que él puede ser.

\subsection{La concreatividad del amor}

Ya Max Scheler había advertido esta capacidad del amor de ver "con los ojos del espíritu" otras cosas (que Scheler, a diferencia de Welte, identificaba con valores objetivos y no con modalidades de "ser-en-el-mundo") ${ }^{19}$ frente a las cuales la actitud racionalista es ciega. Hay en el amor una evidencia propia que no puede medirse por la razón. Igualmente Scheler reconoce que está en relación esencial con el amor la capacidad de percibir lo bueno y lo bello en su potencialidad intrínseca. Tal reconocimiento se expresaría, para el autor,

19 Escribe Scheler: "Pues el hecho de que con los 'ojos del espíritu' del amor y el odio se vean otras cosas (en materia de valores), se vean valores más altos o más bajos que los que se pueden ver con el 'ojo' de la razón, no prueba que todo esto se reduzca en este caso a ver 'peor' lo mismo que con el ojo de la razón se vería 'mejor.'" Max Scheler, Esencia y formas de la simpatía (Buenos Aires: Losada, 2004), 196. (Cursivas mías). Ciertamente Scheler tiene razón cuando afirma la posibilidad del amor de acceder a esferas del ser que no son accesibles, ni siquiera en peor modo, por la razón objetiva. El problema, empero, radica en esta identificación de Scheler de los valores objetivos (que por ser tales son "más altos o más bajos") con el objeto intencionado de un modo específico por el amor. En efecto, si el amor lo es a un valor objetivo, no se ve por qué el amor lo es a un tú específico, puesto que la objetividad del valor puede encontrarse también en otros portadores. Si, en cambio, lo amable es lo que Scheler llama "núcleo de valor", esto es, un núcleo individual "que nunca admite disolverse en valores susceptibles de apreciación separada". Ídem. Entonces cabe preguntarse si efectivamente lo amable y lo visto por el amor es el objeto valor encarnado en el sujeto amado, o el modo en que ese sujeto amado es, aun cuando su "valor" (si todavía queremos usar este término) fuera inferior a otro o realizado menos plenamente de lo que lo realizaría otra persona. Pero si lo amable es el modo en que manifiesta (en acto o en potencia) la amada en su relación concreta con el mundo una cierta belleza o un cierto bien, entonces lo amado no es el "valor", ni siquiera encarnado, sino el "ser-enel-mundo" de la amada como modo de acaecer o temporalizarse de una cierta belleza o bondad que, independientemente de su acaecimiento, no tiene existencia substancial, ni ideal, ni es objeto de amor ninguno. Pero precisamente esta existencia substancial y objetiva, de la que se hace depender el "núcleo de valor" y que sería re-presentada por el amor, es la que Scheler adjudica a los valores comprendidos como entidades axiológicas. En realidad, para una actitud fenomenológica, lo real es lo contrario. Lo que se muestra no es el valor bello, ni ninguna abstracción axiológica, sino el acaecer bellamente y buenamente del ser en el mundo de un existente concreto. Ello es justamente el aporte de Welte que, arraigándose sin dudas en Heidegger, advierte que el amor tiene como objeto lo bello y lo bueno no en tanto valores objetivos, ni siquiera en tanto valores encarnados, sino en tanto modos de "ser-en-el-mundo" y, por ello, propiamente lo amable es lo bueno y lo bello personal, que se halla en devenir y que es, por tanto, irrepresentable. 
afirmando la capacidad del fenómeno de, a partir de un cierto valor dado de un objeto, ver el valor más alto al que apunta. El amor no se reduce, entonces, para Scheler, a experimentar los valores positivos ya dados en una persona antes de entrar él en escena, pues esto también podríamos experimentarlos sin ningún amor por ellas. Por el contrario:

El amor solo existe allí donde al valor dado ya en él 'como real' se añade aún el movimiento, la intención hacia valores todavía posibles y 'más altos' de lo que son aquellos que ya existen y están dados, pero que todavía no están dados como cualidades positivas. Solo como posibles 'fundamentos'de una estructura y una forma total son también estos valores objetos de la intención ${ }^{20}$.

La consecuencia que se extrae de ello es que el amor a una persona concreta esboza siempre "una imagen de valores ideal" que es "tomada a una como su verdadera y efectiva realidad y valía genuina, simplemente no dada todavía en el sentir"21. No se trataría, pues, en el amor de ninguna proyección afectiva ni de una idealización arbitraria o ilusoria, sino que esta imagen ideal de valores estaría ya en germen presente y empíricamente dada en el sentir, pero no como realidad efectiva, sino como "destino [de esa realidad efectiva AG] e imperativo ideal y objetivo de hacerse un todo aún más bello y mejor"22. Justamente en el hecho de reconocer en el amor un movimiento en dirección del ser más alto del valor encuentra Scheler la significación creadora del fenómeno, pero el autor reduce esta creatividad a ser capaz de generar una imagen ideal, y no da el paso siguiente: el de advertir que, por obra de la correlación amorosa, el amante va haciendo ser (sin consumarla nunca) la idealidad entrevista en la realidad efectiva de la persona amada. Es decir, Scheler no advierte que el amor puede ver esta imagen ideal no meramente porque ve los fundamentos que tendrían como "destino" o "imperativo objetivo" una realización ideal (un destino que la mayoría de las veces no se cumple y que, por tanto, no es tal), sino porque comprende que por obra de la específica correlación amorosa la posibilidad de la amada (y del propio amante) de tender hacia un "todo más bello y mejor" adviene a sí, acontece. En 
otros términos, el amor crea, no solo porque ve y configura una imagen ideal, sino porque él, por el modo mismo en que se relaciona con lo bueno y lo bello (incluso germinal) de la amada, va haciendo ser por la correlación lo bueno y bello que ve. Scheler no podía advertir este poder creador ontológico del amor, y no tan solo su creatividad como intuición para percibir figuras ideales, porque daba por sentado como su objeto lo bueno y lo bello en tanto valores objetivos, cuyo ser es independiente de la intuición que los percibe, y no, como Welte, como modos de "ser-en-el-mundo" que acaecen en la correlación con el otro. Por ello no tiene otra posibilidad Scheler que negar rotundamente "que el amor cree los valores mismos o el ser-más alto de los valores" ${ }^{\prime 23}$. Lo cual bien puede ser cierto, si es que hay algo así como valores. Pero lo que en realidad ama el amor es el ser más bueno y más bello, no del valor encarnado en la amada, sino de la amada misma, y este ser se crea en la correlación entre los amantes. Desde su perspectiva, Scheler reduce la creatividad del amor a la esfera del sentir y el preferir ${ }^{24}$ (a la esfera, en última instancia, del conocer en un sentido amplio) y no a la esfera del ser (a la esfera ontológica), en función de la cual está la primera, en cuanto el amor no solo ve sino que, viendo, hace ser lo mejor que hay en nosotros. El amor no solo actúa como causa formal y se representa el fundamento de la imagen ideal ${ }^{25}$, sino que actúa

\section{3 Ídem.}

24 "Pero referido a todo posible sentir y percibir valores, incluso a todo preferir, es decir, relativo a la esfera del sentir y del preferir (...) [el amor AG] hace entrar en la existencia para estas esferas de lo dado valores completamente nuevos más altos." Ibíd., 202.

25 La investigadora italiana Paola Ludovica Coriando nota que el gran aporte de Scheler radica en haber advertido que los sentimientos no son meros estados psicológicos subjetivos, sino que están referidos a un objeto sentido. Constituyen actos intencionales. Pero no de una intencionalidad ciega o confusa, sino que pueden acceder a su propio objeto y hacerlo por cierto de un modo adecuado. Sin embargo, Coriando observa con acierto que el pensamiento de Scheler choca con límites insuperables en su elucidación de la función de la afectividad, provenientes de la presuposición metafísica de que el hombre, según su propia constitución, es un sujeto representativo, que se refiere a través de distintas capacidades a un objeto ya dado previamente. Ya sea que este dado -agregaría yo- en la realidad empírica o como figura ideal. Para Coriando "ambas, la subjetividad del sujeto y la objetividad del mundo exterior, alcanzan a través de la filosofía de los valores de Scheler, nuevos perfiles, que se acercan a los límites de la misma metafísica, pero que no abandonan ni su suelo ni su legalidad". Paola-Ludovika Coriando, Affektenlehre und Phänomenologie der Stimmungen. Wege einer Ontologie und Ethik des Emorionalen (Frankfurt a. M.: V. Klostermann, 2002), 25. Este suelo, a mi modo de ver, recién se abandonaría con la comprensión, de que el objeto del amor no es tal, no es un objeto que ya está dado real o ya subsiste idealmente, sino con la sencilla idea de que este "objeto" no es un núcleo encarnado de valor (Scheler), sino el ser personal del tú amado que está acaeciendo por la correlación misma (Welte). 
como "causa eficiente" y despliega las potencias contenidas en ese fundamento. El haber expresado con suma claridad esta función es el gran aporte de la Dialéctica del amor de Welte. Eros no se representa -ya sea de modo genuino o meramente ilusorio-proyectivo- un objeto ideal dado, sino que hace ser o acaecer lo intencionado (el tú amado) y, haciéndolo, hace concomitante ser al sujeto que intenciona (el yo amante). El amor es con-creativo. No solo ve o reconoce, esto es, no solo se representa (adecuadamente o no) su objeto, sino que dispensa (o, más correcto sería decir, está constantemente dispensando) el seramado de la amada y el ser-amante del amante en la correlación que se establece entre ellos. La capacidad cognitiva o capacidad peculiar de acceso a su objeto, en el caso del eros, cobra su verdadero sentido en clave ontológica, esto es, en función del acontecimiento de llegar a ser el amante el yo que él es y la amada el tú que ella es en función de la correlación que el amor hace posible. A esta función esencial, sobre la base de la cual el amor puede reconocerse plenamente como tal y que constituye su sentido ontológico, se la podría llamar, tal vez, acontecimiento con-creativo.

Este acontecimiento constituye la actividad propia en que se invierte la pasividad originaria del pathos erótico. Y dicha actividad no es otra que conceder-ser. "El amor concede al tú y a lo bueno y bello suyo una nueva dimensión del ser, precisamente la del ser amado"26. Ciertamente el tú amado y sus cualidades respectivas ya los había antes del amor. Pero su ser no se encontraba afirmado ni sustentado, precisamente no-amado, y padecía, por tanto, una falta de ser, una carencia que le impedía desplegar las cualidades de ese, su propio ser. El "no-ser-amado" no es, entonces, una negatividad que simplemente afecta al tú de modo externo, que, por así decir, viene a agregarse ocasionalmente a su ser en un nivel cognoscitivo, impidiendo que se manifieste al otro lo que el tú ya es, sino que "antes bien conciernen este ser mismo y lo menguan en su cualidad como ser"27. El amor precisamente hace ser a lo que le falta ser. No 
es pura pasividad receptiva, no se agota en reflejar la imagen ideal del otro -en ver al otro como Dios lo ve- a partir de ciertos indicios o potencialidades dadas. Él es también y, fundamentalmente, la inversión dialéctica de esta pasividad en aquella actividad que hace ser a lo que aún le falta ser: va convirtiendo al otro en el tú que él ve. En efecto, lo bello que no es visto, lo bueno que no es reconocido carecen, precisamente por esa falta, de la plenitud de su ser. Pero el amor supera esta carencia. "Obsequia al tú amado con su ser"28. Se da aquí una dialéctica paradójica: ya en cuanto el amante se deja determinar pasivamente por lo amable de la amada, afirma y deja emerger activamente este, su ser-amable, concediéndole el seramada en que lo amable se afirma. La acción y la pasión, el obrar y el padecer, resultan, así, en el caso del amor, imposibles de escindir. Y tanto más intensa y manifiesta es esta inversión de la pasividad en actividad cuanto más encubiertos están lo bueno y lo bello amables, "cuanto más oculto está todo ello como posibilidad bajo los oscurecimientos y turbiedades del mal"29. Es precisamente en tales casos donde se advierte la dimensión eminentemente activa y creadora del amor. "Solo el amor puede recrear un nuevo hombre desde sus posibilidades olvidadas y reprimidas, pues solo él es en su pasividad, en su 'encontrarse-tendido-hacia' tan eminentemente activo"30. El amor es poético: da ser a la belleza oculta de los seres. El amante es un poeta y la amada su mejor poema.

Pero el amor no solo es un acontecimiento creativo, sino concreativo. Todo en términos de amor debe pensarse desde su origen como correlación originaria entre un tú y un yo determinados; y también, por cierto, el ser del amante. Gracias a la relación con lo amable, por lo que se encuentra movido y que afirma creativamente en la amada, en el mismo amante emerge lo mejor y más bello de su ser. En términos del propio Welte:

\footnotetext{
28 Ídem.

29 Ídem.

30 Ibíd., 91
} 
El amor es primero movido por lo bello y bueno, luego pro-mueve el libre despliegue de lo bueno y lo bello, pero entonces el brillo de lo bueno y de lo bello vuelve sobre el mismo movimiento amante y se irradia en él ${ }^{31}$.

Dispensando el ser de mi amada encuentro mi propio ser, pues solo puedo ser quien soy, solo puede emerger lo mejor que hay en mí, cuando afirmo el ser de la belleza que mora en quien amo. El poeta hace el poema, pero el poema rehace al poeta.

\section{El sentido cronológico del amor: el acontecimiento sincrónico}

Welte afirma del amor que es como una "vista de la eternidad" ("Blick der Ewigkeit"), aun cuando, considerado "desde fuera" se extienda en las fronteras del tiempo finito ${ }^{32}$. ¿Cómo describir, entonces, positivamente y "desde dentro", esta vivencia de la eternidad? El autor, en su Dialéctica del amor, lamentablemente no va más allá de la aseveración anterior y se limita a advertirnos que "el instante del amor propiamente no conoce tiempo alguno"33. Pero a la relación entre el amor y la eternidad y a la diferencia entre la comprensión del tiempo del amor y la comprensión usual del tiempo también se ha referido otro pensador, que, como Welte, estaba fuertemente influido por Heidegger. Me refiero a Ludwig Binswanger. Estimo que sus análisis pueden ayudarnos a comprender mejor el sentido temporal que cobra el amor en el marco de una comprensión del fenómeno como la weltiana.

Para Binswanger el amor en tanto acontecimiento se temporaliza esencialmente desde el presente. Pero el presente del amor no admite una segmentación temporal. Él no constituye nunca un trecho mensurable que pueda ser completado mediante la adición de espacios de tiempo antepuestos o pospuestos, los que, entonces, aparecerían como su pasado o su futuro. Antes bien, para este autor, el presente del

31 Ídem.

32 Cf. Ibíd., 84

33 Ídem. 
amor se da como "duración eterna" ${ }^{34}$ en tanto constituye una totalidad temporal. ¿ ¿Pero cómo entender esta duración eterna, esta totalidad temporal, en la que los momentos finitos ya no se suceden implacables los unos a los otros? Binswanger la caracteriza recurriendo, como Welte lo hace y como el propio Kierkegaard lo había hecho antes, a la idea del instante y nos habla, entonces, del presente del amor como "instante eterno y lleno de presencia" ${ }^{\prime 35}$. Respecto de la analítica de este presente el autor adhiere explícitamente ${ }^{36}$ a los presupuestos de la comprensión dialógica del tiempo (particularmente Buber), que concibe el presente no como presente en el que algo acontece, sino como presente que el mismo acontece y que es indistinguible de la ejecución o realización (Vollzug) del encuentro intersubjetivo. El presente como dimensión temporal aparece, entonces, aquí como la in-stancia del acontecimiento de encuentro, en el cual el tú, que permanece frente a mí (das Gegen-währende $\mathrm{Du}$ ) como un tú que es la espera de mi respuesta (das Gegen-wartende $\mathrm{Du}$ ), posibilita el presente del yo, que soy esa respuesta que se dirige al tú; y, recíprocamente, el yo, permaneciendo a la espera de la interpelación del tú, posibilita el presente correlativo de ese tú, que es su llamado dirigido a mí. "La temporalidad propia de la duración se basa aquí exclusivamente en el acontecer presente de la relación, que no necesariamente presupone una presencia constituida espacialmente" ${ }^{137}$. Si ahora, sobre esta base dialógica, volvemos a preguntar por la caracterización de la temporalidad del amor, en la que impera el presente concebido como duración eterna del instante del encuentro, nos encontramos con que, para Binswanger, ella tiene una determinación negativa y una positiva. Desde un punto de vista negativo la temporalidad del fenómeno erótico no puede ser comprendida cabalmente ni por el análisis heideggeriano de la temporalidad Daseins (Heidelberg: Asanger Verlag, 1993), 45.

Ibíd., 38.

Ídem.

Michael Schmidt, Ekstatische Transzendenz. Ludwig Binswangers Phänomenologie der Liebe und die Aufdeckung der sozialontologischen Defizite in Heideggers Sein und Zeit (Würzwurg: Könighausen \& Neumann, 2005), 162. 
originaria, que considera el tiempo a partir del advenir a sí a través del precursar la propia muerte (pues el amor, por su estructura dialógica, no piensa en la muerte ni en ninguna otra posibilidad de ser o no ser propia e independiente del tú), ni tampoco por la comprensión vulgar, que considera el tiempo como una línea homogénea, sin fin y, en ese sentido, eterna (pues el instante del amor permanece y todo lo envuelve, no es ni puntual ni pasajero, ni sucesivo ni mensurable, como los instantes del tiempo vulgar) ${ }^{38}$. En lo que respecta a los atributos positivos a través de los cuales se cualifica el concepto de instante ellos son la "eternidad" y la "plenitud de presencia". Binswanger remite lo "eterno" del instante del amor como acontecimiento de encuentro al hecho de que él, en razón de su plenitud, se caracteriza por abarcar el entero horizonte de sentido de la existencia. Él no tiene delante suyo ningún pre-ser-se, no concibe ningún pro-yecto que no esté ya presente en él, envuelto por él, que no sea sino la duración de este presente ahíto en el que me he encontrado plenamente a mí mismo encontrando al otro. En contraposición con la vida (cotidiana) "que pasa y desaparece" el instante de amor "dura" y dura la vida entera que tiene sentido dentro de su horizonte ${ }^{39}$. Por ello podríamos caracterizarlo como "un ya-siempre-haber-llegado del existente" ${ }^{40}$. Y así como este "haber llegado" es experimentado como un "nunca más irse", por lo que el amor no tiene propiamente advenir, así también y en razón de

"El amor 'sabe` ciertamente de estas posibilidades, es amenazado constantemente por la una y por la otra, pero no vive en ninguna de ambas." Ludwig Binswanger, op. cit., 47. En efecto, cuando el amor es supeditado a las posibilidades propias o su tiempo es homologado con cualquier otra ocupación que "llena el tiempo" como tal y propiamente ha desaparecido y constituye solo una forma caída de erotismo.

39 Los instantes de plenitud, que encuentran en el pathos erótico su ejemplo más notable, son, en tanto tales, ajenos al carácter pasajero y ocasional de la temporalidad corriente de la vida. Sin embargo, no están desligados por completo de esa misma vida corriente. Como bien advierte Otto Bollnow en su atinada lectura del tema en Binswanger, "ellos manifiestan su fecundidad para el conjunto de la vida temporal por el hecho de que las ideas asidas durante su transcurso conservan su validez más allá del instante que, como tal, habrá de consumirse, y son capaces de reconfigurar el todo de la vida restante". Otto Bollnow, Das Wesen der Stimmungen (Würzburg: Königshausen \& Neumann, 2009), 95. Ciertamente que el hecho de que "puedan" no significa que lo hagan. El efecto fructífero de estos instantes no le cae al hombre del cielo, sino que depende "del empeño de la vida siguiente si lo asido en estos raros momentos habrá de ser conservado y volverse fructífero o si se desvanecerá nuevamente sin ser empleado". Ídem. 
la misma plenitud que él implica, el presente del amor es vivenciado como un "ya-siempre-haber-sido-ahí" del existente, por lo que el amor no tiene propiamente ningún pasado o sido relevante del cual fuera su emanación extática. En efecto, el yo no ha sido el yo que es ahora; lo es a partir del encuentro con el tú. "Ambos modos juntos de la (supra) temporalización constituyen el instante eterno, el carácter de hogar (Heimatlichkeit) del amor"41, en el que el existente halla reposo en el encuentro con el tú que acoge y salvaguarda el entero horizonte de su existencia. En cuanto a la "plenitud de presencia" ella refiere el hecho de que el instante del amor "concede al tiempo una significación constituyente de sentido, dado que determina de modo cualitativo el sentido de la existencia" ${ }^{42}$. Específicamente lo determina en cuanto constituye el "ahora duradero" a lo largo del cual el existente encuentra colmada o plenificada la búsqueda de sentido para su existencia en el presente dual del nosotros que se origina con el amor ${ }^{43}$.

Valiéndonos de y ampliando estas conclusiones de Binswanger y las afirmaciones de Welte arriba referidas, creo que podría caracterizarse el sentido cronológico del fenómeno, esto es, la obra que él introduce en la temporalización del tiempo como la in-currencia de un acontecimiento sincrónico. Tal aseveración implica distinguir, primero, qué significa que el amor in-curre, y, segundo, que es un acontecimiento sincrónico.

En sentido negativo, que el amor in-curre significa que la duración eterna, a la que Binswanger se refiere, no puede ni derivarse de, ni tampoco configurarse como un movimiento del dis-currir extático de la temporalidad del sujeto, pues ese discurrir no puede dar cuenta de la aparición de la amada ni de su efecto en mí. En sentido positivo

41 Ídem. Respecto de la noción de Heimat en Binswanger como el modo positivo de especialización del espacio en el amor correspondiente a la temporalización del tiempo como duración eterna, sobre la que aquí no podemos explayarnos, cf. Ludwig Binswanger, op. cit., 37. Michael Schmidt, op. cit., 167.

43 En tal sentido escribe Binswanger: "El hacer presente del presente del amor (...) no tiene otro sentido que el darnos lugar uno a otro, yo a ti y tú a mí, pero esto significa que el presente del amor precisamente no reclama la existencia 'como respectivamente mía 'y, como tal, entregada a mí, sino que él da lugar a la existencia (Dasein) para su ahí $(D a)$ en el más profundo sentido del enteramente único pertenecerse uno al otro del nosotros dual, para el hogar (Heimat) del yo y el tú." Ludwig Binswanger, op. cit., 48. 
in-currir debe entenderse de acuerdo con su significación etimológica latina como un "precipitarse en" o "lanzarse contra" y, por ello, "invadir". El acontecimiento del amor se precipita imprevisible en el discurrir continuo del juego de interrelaciones mutuas entre advenir, presentar y sido que configuran la temporalidad extática y la invade por completo, insertando en ella un instante que no es ninguno de sus momentos. ¿̇Cómo acaece tal inserción? A mi modo de ver en los momentos más plenos del pathos erótico el movimiento extático es sobredeterminado por la extrema intensidad del acontecimiento que experimentan los amantes y revierte en lo otro que sí: en concentración de todos los horizontes en el instante de ese acontecimiento que se precipita sobre ellos y los invade. En efecto, en el clímax del pathos erótico, cuando los amantes se sienten plenamente unidos, ni el presente se prolonga en el futuro ni el futuro se prolonga en el presente, sino que, por un instante, la totalidad del futuro, esto es, todo sentido hacia el que puedo advenir, resplandece en el presente, y los amantes viven por anticipado aquella totalidad temporal a la que hacía mención Binswanger. En ese instante de felicidad ab-soluta (esto es, liberada del discurrir extático de la temporalidad finita del sujeto solo que precursa su muerte) los amantes no experimentan ningún devenir hacia futuro alguno, porque el entero futuro, todo aquello con sentido hacia lo que ellos pueden pro-tender-la unidad perfecta y armónica de su ser- se ha anticipado y ya está presente allí. Entonces la muerte, aun cuando no fuese más que fugazmente, se borra del horizonte. Y otro tanto ocurre con el pasado. En la hora feliz del pathos erótico el pasado no es vivido meramente como algo que se prolonga en y que es reiterado desde el presente, sino que, precisamente por la intensidad de ese presente, el entero pasado ya no cuenta (no puede dar cuenta del presente), lo que no significa que no exista, sino que está en su totalidad presente en el presente como lo ya pasado. Cuando los amantes se entregan en totalidad uno a otro, entregan también su entero pasado, el cual está, por tanto, presente en el momento del pathos como pasado sobre-pasado. Anticipación del entero futuro y sobrepaso del entero pasado son las dos 
formas en que los éxtasis se sobre-determinan y pasan de prolongarse hacia e invadir el presente a ser invadidos por y subsumidos en él. Es así que en la consumación del amor el tiempo deja de ser experimentado extáticamente, pero no porque no dure-los amantes despliegan su correlación dia-lógica como tiempo-, sino porque se trata de la duración de un único instante -la "duración eterna" que refiere Binswanger- en el que se concentran todas las dimensiones de la temporalidad. Instante inconmensurable en que los amantes vislumbran la eternidad. Instante que llena el tiempo todo, como el susurro de los amantes llena la noche.

Hemos dicho que el amor es un acontecimiento en el que los amantes en la relación recíproca encuentran plenitud, y que esa plenitud se expresa temporalmente replegando las dimensiones temporales y los horizontes de sentido que ellas despliegan en la incursión de un instante. Si ello es así es porque, en ese instante, se sincronizan el yo y el tú y sus respectivos mundos en una unidad más alta y armónica. El amor es un acontecimiento sincrónico. La noción de sin-cronía no mienta aquí reducción de tiempos diferentes a una síntesis temporal unívoca, sino con-vergencia de temporalidades diversas. Una convergencia que puede durar lo que una caricia o que puede extenderse en el tiempo físico, pero que constituye siempre un único instante, en tanto el momento en que es experimentada la plenitud se recorta, como vimos, de la temporalidad extática y continua del existente, y emerge como un presente nuevo, en el que aparecen armonizados, congregados y ahítos de sentido el conjunto de los tiempos y de los horizontes en los cuales los amantes son. El instante del amor, en que mi vida experimenta el "ya-haber-llegado" a su propia plenitud, es el mismo instante en que la vida colma a la amada y ella alcanza su propia plenitud. Por supuesto, no es que sea el mismo porque dos tiempos diferentes coincidan con un mismo lugar de las manecillas del reloj, sino porque son esencialmente un instante, en cuanto el ahora de mi "ser-en-el-mundo" para darse como ahora de plenitud, necesita que ese ahora sea el ahora de la plenitud del otro y de su mundo. Dicho de modo diferente, el aman- 
te necesita que la amada temporalice ahora su ser en el mundo tal cual ella ahora lo hace, para temporalizarse él en su mundo de modo tal de llegar a ser el yo pleno que él ahora es; y viceversa. Cuando se da tal acontecimiento los dos ahoras se vuelven sincrónicos: se encuentran, complementan y armonizan sus potencialidades hasta un punto tal que se tras-funden uno en el otro con la riqueza entera de los mundos por ellos contenidos, dando origen a un nuevo y más pleno ahora y a un nuevo y más pleno mundo. No otra cosa que esto es la sincronía: que ella haga suceder ahora lo que yo necesito que suceda, para que a su lado todas las cosas me sean amigables. Y es que todo tiene sentido cuando sus ojos y los míos miran juntos.

Si el amor congrega todos los horizontes temporales en un instante sincrónico, en el que, como afirman Welte y Binswanger, dura la eternidad, ello no se debe por cierto a que los amantes se aíslen refugiados en su propio mundillo y en su propio tiempo. Antes bien, cuando el amor es amor verdadero y no egoísmo compartido, la relación entre los amantes da la nota, en la cual, por un instante, cantan al mismo tiempo todas las voces del coro universal.

\section{El sentido cósmico-religioso del amor: el acontecimiento-signo}

Como la propia noción de sincronía lo indica, la correlación amorosa no excluye a los amantes del mundo, sino que se extiende al universo todo. "Pues tanto más grande y fuerte y claro es el amor, tanto más visible se vuelve el hecho de que el amante, amando su tú, a la vez y sin dividirse, lo ama todo"44. Welte acierta con su de- 
claración, porque, gracias al amor que siente por ese tú, el amante des-cubre que ama su propia existencia, que ama existir, y existir es "ser-en-el-mundo", relacionarse con las cosas y con los otros y disfrutar de la propia mortalidad aquí, sobre la tierra y bajo el cielo. Afirmando el tú amado, afirmo a la par mi entera existencia, en cuanto ella es relación al tú. Pero afirmando mi existencia entera afirmo a la par el mundo en que ella es posible y los horizontes en los que ese mundo se sostiene. Afirmo, en una palabra, el universo entero. Y cuanto más intenso y consumado es el amor, cuanto más ajustada es la sincronía entre los amantes, tanto más integral y plenamente afirman ellos su "ser-en-el-mundo" y el mundo en el que son. Por ello vuelve a tener razón Welte cuando sostiene que "el amante afirma el todo, la existencia en general" ${ }^{45}$. Por ello mismo también al amor "todo le es bienvenido y nada le es indiferente, todos los hombres y el cielo y la tierra"46. El amante se siente reconciliado con todas las cosas. Quizás por eso, como el propio Welte recuerda, cuando Dante vio a Beatriz "ya no hubo para él más enemigos"47. Ello no significa, por supuesto, que el amor no pueda ver el mal ni la injusticia entre los hombres, sino que, sufrirá por ellas, y en ese sufrimiento seguirá siendo amor y seguirá confiando en que, más allá de todo mal y de toda injusticia, la vida y el universo tienen sentido. El amor, cuando se consuma, es tan concreto como universal: amo tanto al tú como al mundo, que, reflejado en los ojos del tú, aparece bajo nueva luz. Podríamos incluso decir, para ser más exactos, que, por la luz que irradia ese amor al tú, veo la belleza y la bondad que anida en todas las cosas y, entonces, por y en el amor al tú, amo concomitantemente el mundo todo ${ }^{48}$. Pero si retomamos ahora lo antes dicho acerca de la

\footnotetext{
Bernhard Welte, "Dialektik der Liebe", op. cit., 82.

Ídem.

Ídem.

$\mathrm{Al}$ respecto escribe bellamente Welte: "Pero el amor pleno y desarrollado de acuerdo con su esencia es real y, a la vez, universal. Bien puede ser que en un primer momento se dirija al ser amado, único e individual, así y todo por la fuerza de ese amor van a lucir más bellos el cielo y la tierra, y todos los hombres van a aparecer más amigables a la vista de los amantes, es decir, el todo de aquello que apunta hacia nosotros está sumergido como tal todo en la luz del amor". Bernhard Welte, "Wer an Gott glaubt, muss an alles glauben", op. cit., 83.
} 
sincronía que se da entre los amantes y el mundo entero, que a sus ojos aparece por un instante como una totalidad plena de sentido, es posible decir que en ese instante en que el amor se consuma no solo se muestra la consonancia entre un yo y un tú y, en esa misma consonancia, la consonancia de los amantes con el mundo entero, sino que también, y a pesar de la maldad y el absurdo que desgarran al mundo, se anticipa la consonancia de ese mismo mundo con una promesa de sentido total y pleno para todas las cosas, a la que Welte no duda en llamar lo divino ${ }^{49}$. Precisamente por ello, porque quien ama se siente en todo interpelado por una plenitud infinita e inefable de sentido a la que responde entregando gozoso su existencia, la famosa sentencia que Welte expresa por primera vez en 1978 en su Religionsphilosophie: "Quien cree en Dios debe creer en todo"50 puede parafrasearse sin demasiado esfuerzo y afirmar que "quien ama a un tú debe amarlo todo".

Ya Vladimir Solov'ev, particularmente en el quinto artículo de su obra El sentido del amor ${ }^{51}$, había advertido esta dimensión cósmicoreligiosa del fenómeno y sus implicancias. Observa Solov'ev que el hecho de que la forma más intensa del amor se exprese en la relación recíproca entre dos seres que se complementan mutuamente, no implica, en modo alguno, que esa correlación pueda separarse como algo autosuficiente de todo lo restante. "Por el contrario, un tal aislamiento es el ocaso del amor"52. En efecto, la reunificación completa de dos seres individuales no puede llenarse meramente con la relación sexual, pues, a pesar de toda su importancia subjetiva, desde el punto de vista objetivo ella es un fenómeno empírico de carácter pasajero. Esa completud que experimentan los amantes en tanto tal no puede de ningún modo comprenderse como una forma de vida vacía cerrada en sí, "pues ella [la figura vital que surge de la unión

49 Bernhard Welte, "Dialektik der Liebe", op. cit., 82.

50 Cf. Bernhard Welte, Gesammelte Schriften. Band III/ 1: Religionsphilosophie (Freiburg im Breisgau, Herder, 2008), 164.

51 Vladimir Solov'ev, Der Sinn der Liebe (Hamburg: Felix Meiner, 1985).

$52 \quad$ Ibíd., 56. 
de los amantes AG] por el contrario y de acuerdo con la naturaleza del hombre mismo [su ser como 'ser-en-el-mundo' AG] es capaz de y está determinada a llenarse con un contenido universal" ${ }^{\prime 53}$. $\mathrm{Si}_{\text {, }}$ como veíamos cuando nos referimos al sentido ontológico del amor, en él se da el más alto grado de desarrollo de las posibilidades que el individuo es, y si este desarrollo solo puede alcanzarse existiendo en la más plena unidad y armonía con todo lo que es, entonces es imposible aislar la plenitud como meta de nuestra vida individual de la plenitud del universo en su conjunto. A ello se debe que Solov'ev afirme que, si el amor consiste en reunir dos seres diferentes de modo tal que en esa conjunción cada uno alcance su plenitud individual, el logro de dicha plenitud no pueda separarse del proceso de reunificación o conjunción universal ${ }^{54}$. La ampliación, inherente a la dinámica misma del fenómeno erótico, de la relación de complementariedad experimentada en el amor entre el yo y el tú al ser en general -el paso del amor al tú al amor al universo- no disuelve, sino que consuma la índole específica de la relación entre los amantes, en la medida en que le comunica la unidad de una estructura totalizadora y llena su contenido vital. De ese modo se "eleva y eterniza la forma individual fundamental del amor." 55

Ahora bien, si la plenitud que el amor promete solo se puede consumar absolutamente cuando nuestro amor por el tú implica amar todas las cosas, el uni-verso entero, es decir, aquello uno que a todo reúne y que lo configura como un Cosmos o Todo armonioso, lo inverso es igualmente cierto: la plenitud y armonización universal, de la que el amor erótico entre un yo y un tú forma parte, no puede realizarse sin la obra del amor. Por ello puede afirmarse que el "instante" del amor no es otra cosa que el instante de nuestra participación en el proceso de reunificación o armonización universal, esto es, de la conversión de todas las cosas en un Uni-verso.

\footnotetext{
53 Ídem.

54 Cf. Ibíd., 57.

55 Ibíd., 65.
} 
Como advierte el filósofo ruso, la obra personal del amor toma parte, en la medida en que el amor es genuino y consumado, en "la obra conjunta del mundo entero - la realización e individualización de la idea del Todo-Uno y la espiritualización de la materia"56. Pero para que esta obra se consume y para que, consecuentemente, se produzca la reunificación y plenificación definitiva de todas las individualidades "es necesario que el proceso de integración vaya más allá de las fronteras de la vida social o propiamente humana e incluya la esfera cósmica, de la cual él ha surgido" ${ }^{57}$. La consumación o no de este proceso que Solov'ev vislumbra ni es tarea humana, ni el hombre puede asegurar que tal cosa efectivamente se dé. Solo puede afirmar que necesita tender hacia ella para realizar, cada vez en un grado más alto, su propia existencia. El amor es justamente el modo en que él concreta en su existencia misma esa tendencia. En tanto tal, el amor, en su acontecer mismo, es no la prueba, sino un signo que señala o indica el acaecimiento de un proceso creciente de armonización universal, cuya consumación o no nos supera, pero que, sin embargo, nos sostiene en tanto y en cuanto en él hallamos nuestra propia plenitud. El amor no es signo en el significado usual de un objeto material que por naturaleza o convención representa o sustituye a otro. No es signo objetivamente, pues el amor no es un objeto, sino un acontecimiento. El signo es su propio acontecer, en cuanto este acontecimiento indica efectivizándolo el proceso de armonización de todas las cosas. Por ello mismo el amor es un acontecimiento-signo, que trasciende a los amantes y apunta, re-fiere o señala un sentido ${ }^{58}$ de índole, en última instancia, cósmica. Y en cuanto el amor es propiamente padecido al modo de un don o una virtus infusa, pues nos acaece como una fuerza que traspasa cada vida buscando reunir y armonizar todas las vidas, él es, a su vez, el signo por antonomasia del estar ligados con el Misterio de la vida

$56 \quad$ Ibíd., 58.

$57 \quad$ Ibíd., 66.

58 Uso la palabra sentido aquí en el estricto significado que le da Solov'ev en su obra El sentido del amor. Sentido mienta la vinculación interna de un fenómeno u objeto con la verdad general dentro de la cual él es posible y puede consumarse. Cf. Ibíd., 67. 
y del ímpetu vital que atraviesa el Cosmos todo. Por ello mismo el amor, siendo un acontecimiento-signo de índole cósmica, lo es, a la vez y mucho antes de cualquier interpretación confesional, de índole religiosa. El abrazo de los amantes contiene más que dos cuerpos que se desean. Contiene el misterio del universo entero.

\section{Bibliografía}

Binswanger, Ludwig. Ausgewählte Werke. Band II: Grundformen und Erkenntnis des menschlichen Daseins. Heidelberg: Asanger Verlag, 1993.

Bollnow, Otto. Das Wesen der Stimmungen. Würzburg: Königshausen \& Neumann, 2009.

Coriando, Paola-Ludovika. Affektenlehre und Phänomenologie der Stimmungen. Wege einer Ontologie und Ethik des Emorionalen. Frankfurt a. M.: V. Klostermann, 2002.

Hemmerle, Klaus. "Eine Phänomenologie des Glaubens - Erbe un Auftrag von Bernhard Welte". En Fragend und lehrend den Glauben weit machen. Zum Werk Bernhard Weltes anlässlich seines 80. Geburtstages, editado por K. Hemmerle, 102-122. München/Zürich: Verlag Schnell und Steiner, 1987.

. "Wahrheit und Liebe - ein perichoretisches Verhältnis". En Klaus Hemmerle, Ausgewählte Schriften. Band II: Unterwegs mit dem dreieinen Gott. Schriften zur Religionsphilosophie und Fundamentaltheologie I, 315-322. Freiburg im Breisgau: Herder, 1996.

Welte, Bernhard. "Wer an Gott glaubt, muss an alles glauben". En Bernhard Welte, Gesammelte Schriften. Band IV/2: Wege in die Geheimnisse des Glaubens, 77-86. Freiburg im Breisgau: Herder, 2007.

. Gesammelte Schriften. Band III/ 1: Religionsphilosophie. Freiburg im Breisgau: Herder, 2008. 
. "Dialektik der Liebe". En Bernhard Welte, Gesammelte Schriften. Band V/1: Geistliche Schriften, 78-131. Freiburg im Breisgau: Herder, 2009.

Scheler, Max. Esencia y formas de la simpatía. Buenos Aires: Losada, 2004.

Schmidt, Michael. Ekstatische Transzendenz. Ludwig Binswangers Phänomenologie der Liebe und die Aufdeckung der sozialontologischen Defizite in Heideggers Sein und Zeit. Würzwurg: Könighausen \& Neumann, 2005.

Solov'ev, Vladimir. Der Sinn der Liebe. Hamburg: Felix Meiner, 1985.

Enviado: noviembre de 2011 Aceptado: febrero de 2012 